\title{
Multiple Driver Impacts on Rocky Intertidal Systems: The Need for an Integrated Approach
}

\author{
Charlotte Kunze', Mirco Wölfelschneider ${ }^{2,3}$ and Lena Rölfer ${ }^{2 *}$ \\ ${ }^{1}$ Institute for Chemistry and Biology of Marine Environments (ICBM), Carl-von-Ossietzky University of Oldenburg, \\ Wilhelmshaven, Germany, ${ }^{2}$ Faculty of Biology and Chemistry, University of Bremen, Bremen, Germany, ${ }^{3}$ Leibniz Centre \\ for Tropical Marine Research (ZMT), Bremen, Germany
}

\section{OPEN ACCESS}

Edited by:

Philippe Archambault, Laval University, Canada

Reviewed by:

Nessa O. Connor,

Trinity College Dublin, Ireland Charlotte Carrier-Belleau,

Laval University, Canada

${ }^{*}$ Correspondence:

Lena Rölfer

lena@roelfer.de

Specialty section:

This article was submitted to Global Change and the Future Ocean,

a section of the journal

Frontiers in Marine Science

Received: 12 February 2021

Accepted: 27 April 2021

Published: 19 May 2021

Citation:

Kunze $C$, Wölfelschneider $M$ and Rölfer L (2021) Multiple Driver Impacts on Rocky Intertidal Systems: The Need for an Integrated Approach.

Front. Mar. Sci. 8:667168. doi: 10.3389/fmars.2021.667168
Most intertidal rocky systems are exposed to severe tidal, diurnal, and seasonal changes in environmental parameters. In addition, they show extreme vulnerability to anthropogenic impacts. Research on multiple drivers is therefore crucial to understand the complexity of their potential interactions. Here, we first give an overview of the natural environment and impacts of climate change on rocky shore intertidal systems, and then focus on the impacts of multiple drivers. We further provide a summary of existing multiple driver studies in the literature with the aim for a better understanding of multiple driver interactions. As multiple drivers can affect rocky shore intertidal systems at different spatial and temporal scales, and the outcome of their effects are still more of an "ecological surprise," we recommend a more widespread assessment of the environmental and biological context. We propose a new, integrated approach based on existing literature: this complements previous frameworks but with an improved understanding of co-occurring multiple driver systems of the rocky intertidal, in order to find management solutions based on accurate and informed predictions in these times of global change.

Keywords: climate change, ecosystem stability, driver fluctuation, life stage dependency, multiple drivers, multiple stressor, rocky shores

\section{INTRODUCTION}

Rocky shores have a global distribution and are generally well-studied ecosystems that have been investigated for several decades (Menge, 1976). A number of ecological concepts originate from rocky shore research, e.g., competition, coexistence, and diversity (Menge, 1976; Connell, 1985; Branch, 2001; Worm and Karez, 2002; Hawkins et al., 2008, 2020). The dynamic properties of rocky intertidal shore make them an excellent model system for understanding changes in community structure and functioning (Hawkins et al., 2008), as well as for investigating impacts of single and multiple anthropogenic driver(s) acting upon them.

In this review we focus on climate change, as its impacts occur on a global scale-making its integration into research and management practices of high relevance. Exploring the interaction of climate drivers with natural and other anthropogenic drivers is of great importance in order to understand where additive, synergistic or antagonistic relations may occur, which will subsequently determine management plans. Furthermore, we refer to "drivers" rather than "stressors," as "stressors" imply a negative impact, whereas "drivers" can include mitigating effects (Boyd and Hutchins, 2012; Boyd et al., 2018). 
This review will provide an overview on (1) the natural environment of rocky intertidal systems and its response to natural drivers, (2) the anthropogenic drivers affecting the natural environment, and (3) multiple driver interactions and their influence on rocky intertidal systems, with particular regard to climate change. Building on this, we further investigate the current challenges regarding multiple driver research on rocky shores and discuss how those can be tackled in future studies. Finally, we propose an integrated approach of rocky shore research aiming for better predictions of the impacts of multidriver changes; ultimately improving management solutions toward a sustainable relationship between humans and rocky shore ecosystems.

\section{The Natural Environment of Rocky Intertidal Systems and Its Response to Natural Drivers}

Rocky intertidal systems exist at the interface of land and sea, which is why the biogeographic ranges of its species are determined by various terrestrial and oceanic factors. Natural environmental drivers can be physical (desiccation, heat and cold stress, extreme salinity conditions, and wave action) as well as biological (competition for space and predation) (see Figure 1A), all of which lead to varying distribution patterns depending on local environmental conditions (Underwood, 1972, 1981; Hawkins et al., 2020). Physical parameters often increase in intensity toward the vertical boundaries of the shore, promoting a vertical zonation of species based on their tolerance to extremes of any of these drivers. The lower limit of intertidal species is defined primarily by biotic factors such as competition and predation (Connell, 1961). For sessile organisms, the upper zonation is limited by physiological stress due to environmental conditions. Mobile species, however, often live within their "zone of comfort" (Branch, 2001), by choosing their habitat, which can depend on the availability of prey or refuge from predators.

Due to the exposed location of rocky shore species at the landsea interface and the number of potential drivers affecting them, environmental impacts on rocky shore species are often more severe than in other coastal ecosystems (Thompson et al., 2002; Branch et al., 2008). This results in a pronounced disturbance history of rocky shore communities and demands their ability to frequently adapt to changes in the environment (Mieszkowska, 2016). Ecological memory is therefore an important feature of intertidal species and is defined as an assemblage of species and habitats in a particular location, which facilitates recovery following disturbance (Nyström and Folke, 2001; Berkes et al., 2004). Indeed, it is especially those individuals that faced a previous disturbance that have a greatly improved response performance during subsequent disturbances, and they are likely to recolonize and reorganize the system (Walter et al., 2013). Species characteristics such as tolerance of disturbance, generation time, and dispersal facilitate the adaptation capacity of rocky shore ecosystems (Bernhardt and Leslie, 2013). In fact, many studies found an increase in more tolerant species after multiple disturbances compared to single disturbances (e.g., Breitburg et al., 1998; O’Connor and Donohue, 2013; Johnson et al., 2015).

Further, the high biological diversity of rocky shores promotes ecosystem stability (Bernhardt and Leslie, 2013), including the ability to withstand, absorb and/or recover from disturbances, which is reflected in dimensions of resistance, resilience, recovery, or temporal invariance (Donohue et al., 2013; Hillebrand et al., 2018; Box 1). In a functionally diverse ecosystem [referring to a functional group as a pool of species which resemble one another because of their biogeochemical attributes (Naeem, 2008)], ecosystem functioning can be maintained when many species of a functional group are present (Walker, 1995; Naeem, 2008; Griffin et al., 2009), because species extinction can be compensated (Yachi and Loreau, 1999). This "functional redundancy" is a key concept in ecology, and one of the major reasons for the high tolerance of rocky shores to natural drivers (Loreau, 2004; Naeem, 2008). Consequently, diverse rocky shore communities often have an increased capacity for recovery following disturbance (Walker, 1995; Tilman et al., 1996; Naeem, 2008). Moreover, the strength of species interactions can either stabilize or destabilize rocky shore ecosystems (Bernhardt and Leslie, 2013; White et al., 2020). For example, if species interactions are strong, the loss of one key species results in higher susceptibility to disturbances (Menge, 1976; Arnott and Vanni, 1993; Crooks and Soulé, 1999; Jackson et al., 2001). Rocky shore ecosystems have a high complexity in their trophic compositions and competitive interactions (Connell, 1961; Paine, 1974). Predator presence or absence not only defines intertidal zonation but also contributes to the underlying community structure (Paine, 1974; O'Connor and Donohue, 2013; O'Connor et al., 2015; White et al., 2018). Thus, the removal of one key predator such as the sea star Pisaster ochraceus can have great effects on community composition, resulting in the competitively superior prey gaining dominance and a subsequent decline in biodiversity (Paine, 1974).

Concepts such as functional redundancy, biodiversityecosystem functioning, and ecological memory are some of the important ecological theories developed by observing the properties of rocky shore communities, which may help to maintain stability. Despite the fact that intertidal rocky shore communities have evolved along varying environmental conditions and natural drivers, they already live very close to their tolerance limits (Deutsch et al., 2008). Under more extreme conditions, those limits might be exceeded, e.g., threshold heat tolerance can be surpassed under increasing sea surface temperatures (SST) caused by climate change. Therefore, experiencing extreme weather events and seasonal/diurnal fluctuations in addition to natural drivers might affect the ability of rocky shores to withstand disturbances and drastically alter ecosystem structure and functioning (Hughes et al., 2019). This will be further discussed in the next sections.

\section{Anthropogenic Drivers Acting on Rocky Intertidal Systems}

Intertidal rocky shores are severely threatened by climate change and other anthropogenic drivers (Figure 1B; 


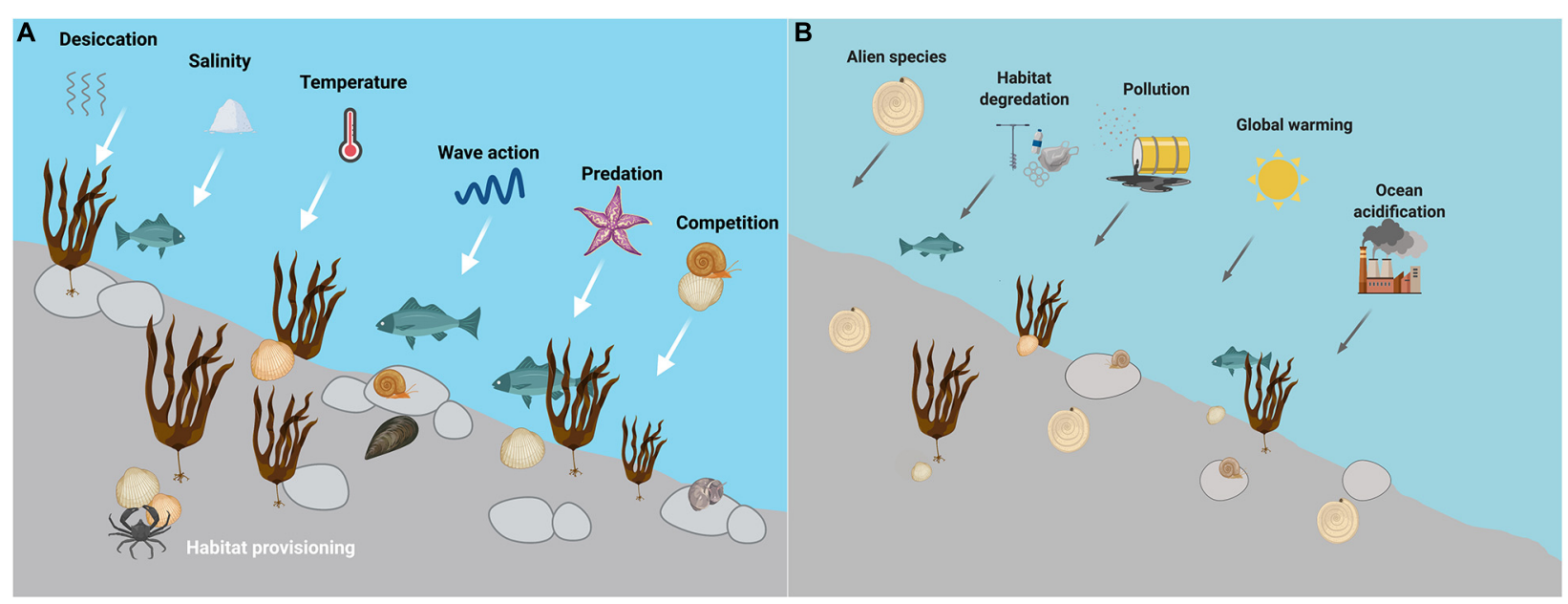

FIGURE 1 | (A) Natural and (B) anthropogenic drivers acting on rocky intertidal systems. In an undisturbed environment, mainly abiotic factors (such as wave action, temperature, salinity, and desiccation) limit the upper species zonation, whereas biotic interactions (e.g., predation and competition) shape the lower species zonation. Local anthropogenic drivers such as alien species introductions, habitat degradation, and pollution, as well as global anthropogenic drivers such as global warming and ocean acidification act on top of natural drivers and increase the level of stress on intertidal species. Pollution comprises drivers such as eutrophication, oil spills, toxins, endocrine disruptors, and toxic algal blooms. The drivers indicated in this figure are not exclusive, but synthesize the main drivers identified in this review. The arrows are not indicative of drivers affecting different intertidal zones.

Thompson et al., 2002; Doney et al., 2012). With the increasing intensity of anthropogenically-driven changes, rocky shore species are experiencing more intense stress at local, regional, and global scales. Impacts of various drivers such as pollution, exploitation by humans, introduction of alien species, man-made alterations to coastal geomorphological processes, and large-scale phenomena on rocky shores have been well reviewed in the past (Thompson et al., 2002; Branch et al., 2008; Mieszkowska, 2016). As global warming is an "umbrella" driver prevalent across systems (Jackson et al., 2021), we will focus specifically on climate driver impacts on rocky shore intertidal systems in this section.

Anthropogenic activities have resulted in increased atmospheric $\mathrm{CO}_{2}$ levels and a subsequent rise in air and SST (Stocker et al., 2013; Hoegh-Guldberg et al., 2018). Such increases in temperature have already led to changes in the abundance and distribution of intertidal species: it has been shown that warm water species are becoming more abundant, while those species adapted to cold water conditions are either moving poleward (Hawkins et al., 2008; Pitt et al., 2010; Wernberg et al., 2011) or contracting their ranges (Smale et al., 2017). The latitudinal shift in species distributions can vary from a few kilometers to a few hundred kilometers (Branch et al., 2008). Range shifts will lead to alterations in community composition and, therefore, may affect ecosystem structure and functioning (Hawkins et al., 2008; Mieszkowska, 2016). Helmuth et al. (2002) proposed that a poleward shift in the distribution of intertidal organisms, however, may not be a general rule. They argue rather that "hot spots" of thermally stressful conditions will lead to a set of local extinctions (Helmuth et al., 2002, 2006).

In recent years, research about extreme climatic events such as marine heatwaves (MHW) has vastly increased (e.g., Wernberg et al., 2013; Oliver et al., 2018; Holbrook et al.,
2019; Smale et al., 2019). Due to climate change, the frequency and duration of MHWs is generally increasing (Oliver et al., 2018). In 2011, a warming event along the west coast of Australia caused a shift in rocky shore community structure from habitat-forming seaweeds toward a depauperate ecological state (Wernberg et al., 2013). The latest MHW on the South Island of New Zealand during the summer of 2017/2018 led to high mortality and local extinction of the iconic bull kelp, which is an important ecosystem engineer; it provides habitat and promotes biodiversity and ecosystem functioning (Thomsen et al., 2019). It is assumed that discrete extreme events now drive drastic shifts in community structure (Wernberg et al., 2013; Smale et al., 2019) due to the underlying mean warming of the oceans (Oliver, 2019). Ultimately, MHWs might be threatening the biodiversity and ecosystem functioning of marine ecosystems (Smale et al., 2019).

Ocean acidification is another result of climate change, and is a consequence of increased atmospheric $\mathrm{CO}_{2}$ dissolving in the oceans, causing a reduction in seawater $\mathrm{pH}$ (Harley et al., 2006). This has various impacts on calcifying species and macroalgae, particularly on their earlier life stages (Przeslawski et al., 2015). Calcifying species such as barnacles, limpets, and top-shells are most vulnerable to ocean acidification and have been affected especially during the second half of the century (Mieszkowska, 2016). However, to which extent calcifying organisms along the world's rocky shores will be affected is still a subject of discussion. For example, the barnacles Semibalanus balanoides and Austrominius modestus can deal comparably well in acidified conditions (Findlay et al., 2009), whereas the barnacle Amphibalanus amphitrite exhibits severe reduction in shell stability (Nardone et al., 2018). Marine gastropods are assumed to be more affected in their predatory behavior and are more vulnerable 


\section{BOX 1 | The concept of ecological stability.}

Ecological stability can be defined by the response of an ecosystem to a given perturbation and includes the ability of an ecosystem to withstand, absorb, or recover from disturbances and return to initial baseline conditions (Pimm, 1984). The response to change is multidimensional and can be broken down into the following components: withstanding the change (resistance), recovering from it (recovery success), speed of recovery (resilience), and temporal stability (measure for variability around the recovery trend) (Donohue et al., 2013; Hillebrand et al., 2018). Recovery of a system is most complete when either resistance or resilience is high (Hillebrand et al., 2018; Hillebrand and Kunze, 2020). Further differentiation between the stability of ecosystem function (processes such as the production of biomass or species cover) and composition (structure of the community-presence or absence of different species from a regional species pool) is necessary (Hillebrand et al., 2018). With a univariate understanding, we significantly underestimate the potential of disturbances to destabilize ecosystems.

to predation themselves under rising ocean acidification (Queirós et al., 2015).

Juvenile stages of marine organisms are shown to be most sensitive to changing environments (Przeslawski et al., 2015). Manríquez et al. (2016) showed that ocean acidification altered behavior and reduced metabolism and growth rates in a juvenile marine gastropod (Concholepas concholepas). Furthermore, marine larvae and eggs are assumed to be worst affected and, in some scenarios, will in some regions not reach the calcifying stage (Byrne, 2011), which would have immense consequences for subsequent generations and the distribution range of calcifying organisms.

The effects of ocean acidification on macroalgae will be complex due to the promotion of photosynthesis with increased atmospheric $\mathrm{Co} 2$, but an unknown effect of increased $\mathrm{pH}$ (Johnson et al., 2015; Mieszkowska, 2016; Cornwall et al., 2017; Zweng et al., 2018). Both the studies of Cornwall et al. (2017) and Zweng et al. (2018) have revealed a strong, positive correlation between the growth performance of macroalgae and their ability to use $\mathrm{HCO}_{3}^{-}$as a source for photosynthesis. This ability is seemingly more strongly promoted in fleshy algae, which are not obligate calcifiers. However, the overall situation is more complex: during earlier life stages, macroalgae are likely to be more vulnerable to acidification. This would potentially negate the positive effects of increased $\mathrm{pCO}_{2}$ in the water column for later-stage fleshy algae, and even have the potential to amplify the negative effects seen in adult algae of calcifying species (Guenther et al., 2018). Furthermore, on a community level, the effects of ocean acidification are often much more complex and difficult to predict. A study by Connell et al. (2017), for example, showed that increased algal growth due to increased $\mathrm{CO}_{2}$ availability could sustain more gastropods compared to areas with lower dissolved $\mathrm{CO}_{2}$. Furthermore, ocean acidification not only impacts the benthic organisms and community structure on rocky shores, but also the overall environmental conditions (Kroeker et al., 2017). Heavy metals, for example, are assumed to dissolve better under rising $\mathrm{pCO}_{2}$ levels and, therefore, increase in their toxicity (Millero et al., 2009).

Overall, it is evident that multiple driver impacts on both single organisms and communities will further increase with ongoing climate change (Byrne, 2011; Przeslawski et al., 2015; Wong and Candolin, 2015; Mieszkowska, 2016; Kroeker et al., 2017). The response of intertidal species and community structure to anthropogenic drivers can be diverse, as described in this section. With climate change as an "umbrella" driver underlying various driver interactions, we will further explore the impacts of multiple driver interactions under climate change in the following section.

\section{Multiple Driver Interactions Under Climate Change and Their Influence on Rocky Intertidal Systems}

Under mounting human pressure, it is critical that we understand how multiple drivers may interact to further negatively impact rocky shore intertidal ecosystems (Crain et al., 2008; Piggott et al., 2015). Harley et al. (2006) noted that research on synergistic effects between climate and other anthropogenic factors is needed at the population or community level, as these additional drivers will "likely exacerbate climate-induced changes."

The outcome of multiple-driver scenarios cannot be predicted by single-driver experiments alone due to the complexity of potential interacting effects among drivers and their physicochemical dynamics (Przeslawski et al., 2015; Gunderson et al., 2016; Boyd et al., 2018; Cimon and Cusson, 2018). Such interactions can be synergistic or antagonistic (Piggott et al., 2015; see Box 2 for a detailed description). In recent years, the study of multiple drivers has increased (Przeslawski et al., 2015; Nõges et al., 2016). Here we give an overview of recent research on the interaction of multiple drivers in intertidal rocky shore ecosystems with regard to climate change.

In general, UV radiation, temperature, salinity, $\mathrm{pH}$ and toxins are the most researched drivers in multiple driver studies on rocky shore species (Crain et al., 2008; Przeslawski et al., 2015; Stockbridge et al., 2020). Driver combinations include often salinity, nutrients, $\mathrm{UV}$, and $\mathrm{pH}$, respectively, with temperature (increase). While global meta-analyses on multiple driver impacts on marine systems (Crain et al., 2008) and on early life stages (Przeslawski et al., 2015) have found mainly synergistic effects when considering two or three drivers, a recent meta-analysis of the impact of multiple drivers on seaweeds found mostly additive effects (Stockbridge et al., 2020). These apparent contrasting results emphasize that the impact of multiple drivers is not universal. Indeed, drivers can affect ecosystems at various spatial and temporal scales (Jackson et al., 2021) requiring differentiation between local and global drivers (Hawkins et al., 2017; Kéfi et al., 2019). Climate change, for example, is a global phenomenon; however, its related changes such as sea-level rise will not occur uniformly at the local level (Stachowicz et al., 2002; Hawkins et al., 2017), as it is also influenced by regional or local geomorphological features (Doney et al., 2012). The impact of multiple drivers on rocky shores differs with regard to whether they act globally, regionally, or locally (Wernberg et al., 2011). Furthermore, the influence of other drivers, such as eutrophication, is more pronounced than in many other marine systems (Thompson et al., 2002; Branch et al., 2008). A study by Strain et al. (2015) found that the reduction of local drivers, such 


\section{BOX 2 | Multiple drivers - a definition.}

In the multiple-driver literature, there have been various approaches for how to define a driver (Orr et al., 2020). Folt et al. (1999) proposed an operational definition of a stressor, stating that stress is a decrease in fitness or survival when compared to optimum conditions. In their observational study on multiple disturbances on a coral reef, Hughes and Connell (1999) defined multiple stressors as both "natural or man-made disturbances." A more recent definition of a stressor by Côté et al. (2016) has a more theoretical approach, defining a stressor as a natural or anthropogenic action that causes a change in biological response, which can be either positive or negative. As the term "stressor" implies a negative impact, we use the term "driver" as proposed by Boyd and Hutchins (2012). The same driver might enhance a certain physiological response in one organism, while stressing another. In the latter case, the term stressor might still be used.

Due to the fact that all natural conditions are highly affected by human actions, we simplify "multiple drivers" as the combination of two or more impacts on an ecosystem causing a change in community composition or ecosystem functioning that can be either negative or positive (modified from Piggott et al., 2015). There are two different types of interactions between multiple drivers (Folt et al., 1999). Interactions between drivers can be either synergistic (disproportionately increased impact), or antagonistic (decreased impact) as shown in Figure 2. The classification of interactions can be done by using two different null models. The "additive null model" $(\mathrm{A}+\mathrm{B})$ is derived by building the sum of the interactions. This null model can easily be used for continuous response variables such as growth, Chlorophyll a concentration, or shell mineralization, but can cause problems when being applied to limited response variables such as mortality (Piggott et al., 2015; Côté et al., 2016; Carrier-Belleau et al., 2021). For such variables using a "multiplicative null model" (A+B-A*B) can correct over-estimations exceeding 100\%. An antagonistic effect appears when the combined effect of two or more drivers is lower than the chosen null model based on the single drivers, whereas a synergistic effect exceeds it.

Piggott et al. (2015) enhanced this definition of a synergistic effect and emphasized the need for a directional context when defining interaction effects. Resulting interaction-type effects considering the direction of driver effects are:

- antagonistic effect: positive antagonistic, when the interaction effect of drivers is greater than the positive additive effect; or negative antagonistic, when the interaction effect of drivers is less than the negative additive effect.

- synergistic effect: positive when the driver effects are greater than the positive additive effect and negative when driver effects are less than the negative additive effect.

Thus, the response type is highly dependent on whether the interaction types have "double-positive," "double-negative" or "opposing" effects

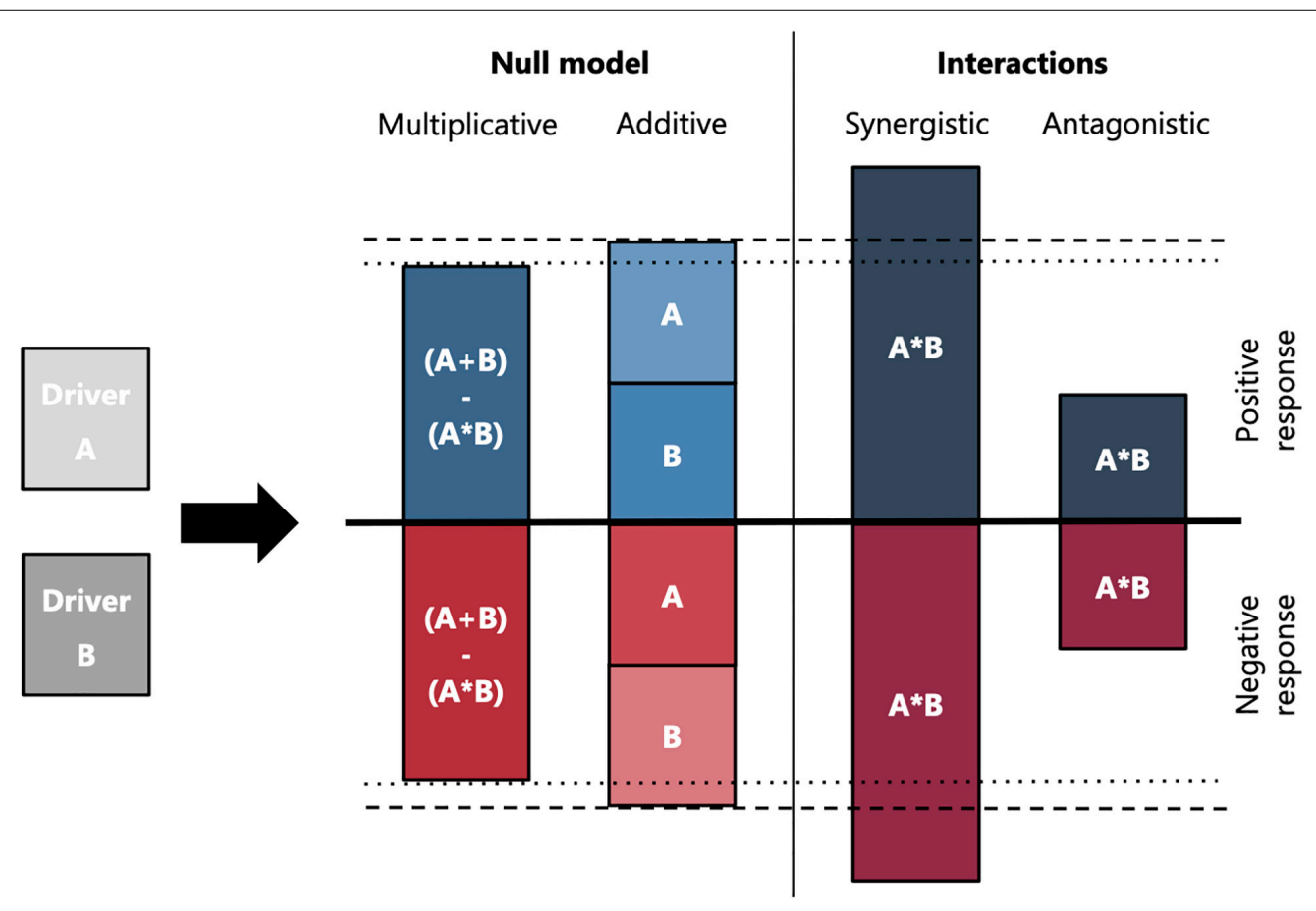

FIGURE 2 | Overview of different driver interactions between two drivers. The interactions can be classified by using two different null models. The additive null model $(A+B)$ is derived by building the sum of the interactions. A multiplicative null model $\left(A+B-A^{*} B\right)$ can correct over-estimations for factors such as mortality. Either of the classifications can be assigned a synergistic or antagonistic interaction of the drivers, which can act beneficial or deleterious compared to the null model. The height of bars indicates the magnitude of the response and the direction indicates a positive or negative response compared to a control (e.g., undisturbed habitat). The dashed lines indicate the magnitude of a multiplicative and additive null model, respectively.

as sediment load and nutrient concentrations, would improve the resilience of a rocky shore foundation algal species to global climate drivers, such as increasing SST and high wave exposure. Similarly, Hawkins et al. (2017) investigated the recovery of rocky shore assemblages from an oil spill in the southwest of England, and tested how this recovery was affected by climate change. They point out that even though local pollution events and habitat degradation are not the most worrying threats to marine 
ecosystems in times of global change, adaptive management of controllable factors such as eutrophication from agriculture and sewage will positively affect the ecological resilience to global warming over the next 40-50 years (Hawkins et al., 2017).

In climate change scenarios, coastal regions such as rocky shores will be more affected by cumulative stressors (Halpern et al., 2015), and, therefore, the ability of rocky shores to withstand multiple drivers becomes an important trait. Studies about the impact of multiple drivers on the resilience of rocky shore communities are rare. In a recent study, Cimon and Cusson (2018) applied a full factorial experimental design to test the effect of an initial short-term driver (pulse disturbance) and three following constant drivers (press disturbances) on a benthic intertidal community. Comparing grazer reduction, canopy removal and nutrient enrichment, they found synergistic effects when driver combinations included nutrient enrichment. As single driver, canopy removal had the most pronounced effect on composition and function, resulting in a changed community structure (Cimon and Cusson, 2018). They found that recovery was never achieved after introducing those three drivers. Similarly, anthropogenic drivers, such as trampling, can resemble natural drivers, such as storms, in their extent of destruction and effects on rocky shore communities (Micheli et al., 2016). Contrasting to other studies, Micheli et al. (2016) determined a synergistic rather than an additive effect of human trampling and a storm on a rocky shore community. This further emphasizes that driver interactions are not universal for similar habitats (Micheli et al., 2016), but that the effect of drivers on an ecosystem is highly context-dependent and can be driven by temporal variability within a population or community (Mrowicki et al., 2016). Moreover, species characteristics of the community such as species co-tolerance (or "stress-induced community tolerance") to introduced drivers determines whether ecosystem function can be maintained through change (Vinebrooke et al., 2004). For example, Sampaio et al. (2018) found that the outcome of a multiple driver experiment changes in response to the order that the driver combinations $(\mathrm{pH}, \mathrm{MeHg}$, and temperature) were introduced. $\mathrm{Hg}$ accumulation in body tissues (i.e., the liver) in combination with elevated temperatures displayed a synergistic behavior. On the other hand, elevated $\mathrm{CO}_{2}$ concentrations (increased $\mathrm{pH}$ ) antagonistically interacted with the $\mathrm{Hg}$ accumulation in the tissues and oxidative stress caused by Hg contamination, which increased temperature-this resulted in reduced levels of those variables, i.e., antagonistic behavior. The ecological impacts of climate change could therefore be "dramatically underestimated" if the interplay of multiple drivers is not considered (Przeslawski et al., 2005).

Furthermore, the difference in stressor impacts for various life forms demands research with regard to multiple anthropogenic drivers across the range of life history stages (Vye et al., 2017). The early life stages of intertidal species are crucial for the structure and function of adult populations on rocky shores and should be taken into consideration when investigating the effects of anthropogenic drivers (Connell, 1985). Different factors such as counteracting effects of other environmental factors, adaptive capacity, or genetic variability might mask or fully cancel negative influences of changing drivers for the full range of stages (Ross et al., 2011; Cole et al., 2016; Espinel-Velasco et al., 2018)., As mentioned above, there is growing evidence that early marine life stages such as eggs, larvae, and juveniles are more sensitive to environmental changes (Altamirano et al., 2003; Thiyagarajan et al., 2003; Ushakova, 2003; Espinel-Velasco et al., 2018). One study on encapsulated early life stages of rocky shore gastropods found that species inhabiting the lower shore had the highest mortality (90\%) when exposed to ultraviolet radiation, water temperature stress, and salinity stress (Przeslawski et al., 2005). The effects of single drivers differed in their magnitude, with UV radiation causing the highest mortality. They further observed a synergistic effect on mortality and retardation in development when introducing multiple drivers. Similarly, a multiple-driver experiment by Ko et al. (2014) revealed a reduced larval growth rate just before the crucial phase of settlement and metamorphosis in pacific oysters, when experiencing elevated temperature as well as decreased salinity and $\mathrm{pH}$. This is why it is important to consider different life stages but also the scale and space dependencies of climate change drivers when investigating multiple driver impacts on rocky shore systems, but especially when predicting the response of rocky shore species to future drivers.

\section{CHALLENGES IN CURRENT RESEARCH ON MULTIPLE DRIVERS AFFECTING ROCKY INTERTIDAL SYSTEMS}

Regardless of the studies conducted, multiple driver effects tend to be "ecological surprises" (Paine, 1974) and need to be further studied to gain a better understanding of how intertidal rocky shores will be affected in the face of climate change. Here, we provide an overview of challenges in current research in order to discuss both knowledge gaps and limitations to experiments on rocky shores. We consider various dimensions of multiple drivers with regard to their spatial and temporal dependency, upscaling from individual to community responses, and correlation with biological factors such as community structure, predation and competition.

The difficulty in finding generalizing patterns that explain how drivers might act alone and in combination is linked to the high number of environmental factors involved. Such factors can vary on a regional level (such as nutrients, sedimentation, etc., Wernberg et al., 2011), but also on smaller spatial scales. For example: $\mathrm{pH}, \mathrm{pCO}_{2}$ and temperature levels at one rocky shore site can change multiple times over the period of 1 day (Gunderson et al., 2016). A growing body of literature is moving toward more complex experimental set-ups by including two or more drivers (Blake and Duffy, 2010; Cimon and Cusson, 2018; Kéfi et al., 2019) to better understand the interaction effects of different drivers acting simultaneously. Most of these studies focus on physical parameters; often investigating the combined effects of temperature and salinity or temperature and $\mathrm{pH}$ (Crain et al., 2008; Przeslawski et al., 2015; Gunderson et al., 2016). Over the past decade, with increased understanding of the mounting pressure that marine systems are facing, studies are emerging that focus on three, four, or more drivers (Bertocci et al., 2010; 
Przeslawski et al., 2015). The findings of such complex multiple driver studies deliver more meaningful results, as they likely better represent our natural systems, at least in terms of the quantity and identity of threats.

However, a realistic implementation of multiple drivers in experiments is not as easy and trivial as many studies have assumed it to be. The examples of tide pools and rocky shores reveal differences in temperature, $\mathrm{CO}_{2}$, and $\mathrm{pH}$ variations occurring during 1 day, which highlights the importance of fluctuating environments and the temporal sequence of stress events (Gunderson et al., 2016). Such fluctuations on driver levels do not only occur on small timescales. The outcome of multiple stressor introduction is therefore subject to change depending on the order in which stressors are introduced (Breitburg et al., 1998; Vinebrooke et al., 2004; Gunderson et al., 2016). If stressors are added consecutively instead of simultaneously, the response to the second stressor might change after exposure to an initial stressor because of a shift in community composition and, as a consequence, an altered sensitivity of the community (Crain et al., 2008). Moreover, certain stressors are coupled in their intensity, e.g., nutrient enrichment can enhance the effects of warming on ecosystem productivity, and their effects are density- and species-dependent (Staehr and Sand-Jensen, 2006; Brooks and Crowe, 2018; White et al., 2018). By increasing solely the mean temperature, $\mathrm{pCO}_{2}$, or $\mathrm{pH}$ in experiments, capturing the effect of diurnal or seasonal variability, or extreme events is not possible (Kroeker et al., 2020). There is an increasing awareness that to make reliable predictions of future climate change, we need not only the mean values of extreme events, but also their frequency, magnitude, and spatial extent (Wernberg et al., 2013; Vye et al., 2015; Stockbridge et al., 2020). This is also reflected in the rising amount of literature investigating fluctuating vs. constant driver regimes (e.g., Fong and Fong, 2018; Oliver et al., 2018). The experimental burden of such complex studies, in terms of time and resources, requires a calculated prioritization of relevant drivers in the system, as well as a realistic regime of frequency, magnitude, and sequence of the selected drivers (Crain et al., 2008; Jackson et al., 2016; Boyd et al., 2018). Although hypothesisdriven experiments with clear ecological application and context have been developed in the last decades (Hawkins et al., 2020), we still tend to over- or underestimate the impact of multiple drivers. For more realistic experimental scenarios and the design of nearnatural treatments, Global Circulation Models (GCMs) can be used in combination with weather generator models assessing climate projections on a local scale (Thompson et al., 2013; Korell et al., 2020). Alternatively, "transplant" field experiments are an effective tool to account for direct and indirect effects of the environment (Hawkins et al., 2020).

Expanding the scope from an individual to a community level is a highly complex undertaking. An generalization approach was made by Queirós et al. (2015), who modeled the distribution of the marine gastropod Nucella lapillus under three IPCC scenarios. Based on the results of a lab experiment, they concluded that spatial distribution cannot be accurately predicted from single-species experiments. Harley et al. (2006) revealed that $\sim 60 \%$ of climate publications look at an individual level, $\sim 30 \%$ at a population level, and only $\sim 11 \%$ at a community level. In a multiple driver system, community-level recovery dynamics become more complex and less predictable. Thus, there is a need for more research at the community level. As summarized by a recent review (Jackson et al., 2021), the easiest way of upscaling from individual to community and ecosystem responses should include a consideration of species' metabolism by e.g., using biomass-weighted sum of individual responses to one or more drivers.

Furthermore, the way multiple drivers interact is highly context-dependent. While Jackson et al. (2016) found that in freshwater systems, the net effects are antagonistic, Crain et al. (2008) found an overall synergistic effect in marine and coastal systems. Their meta-analysis indicates that a community's response to multiple drivers depends not only on the number of drivers that are introduced to a system, but certainly their intensity as well as their sequence. By adding one single driver to a set-up and increasing the total driver number from two to three, the interaction type changed significantly. Moreover, their study revealed that the interaction type depends on the response level (community: antagonistic, population: synergistic), as well as the trophic level (autotrophs: antagonistic, heterotrophs: synergistic). Another important aspect to be considered for predicting responses at community levels are biological interactions. There are multiple inter- and intra-specific interactions such as competition, and secondary benefits such as habitat provisions from keystone species (Bertocci et al., 2010; Cimon and Cusson, 2018), that can alter the responses to multiple drivers. White et al. (2018) demonstrated in a mesocosm experimental setup that predator-species composition could mitigate the effect of warming and nutrient enrichment on marine rocky shore communities. Another study by Bertocci et al. (2010), focusing on the buffering effect of canopy-forming macroalgae while the community was exposed to other anthropogenic stressors, showed the antagonistic nature of these interactions.

Due to the interactions between physical and biological processes, organismal contributions are difficult to predict as they are not always linear (Branch et al., 2008; Bertocci et al., 2010; Kroeker et al., 2017) and are not easily reproducible under laboratory conditions. However, it is clear that biodiversity is the key to ecological resistance and recovery capacity under complex disturbance regimes (Townsend et al., 1997; Bertocci et al., 2010; White et al., 2018). Within their study on how grazer diversity affects different responses in a multiple driver mesocosm setup, Blake and Duffy (2010) revealed that $80 \%$ of measured responses were antagonistic. This contradicts the overwhelming majority of synergistic responses reported from other meta-analyses (Ban et al., 2014; Gunderson et al., 2016). Furthermore, the inclusion of the most vulnerable juvenile states, such as eggs and larvae, in studies is another crucial aspect of biological factors often overlooked by the scientific community (Przeslawski et al., 2015). In some cases, highly specialized and poorly understood life cycles of rocky shore species can hinder comprehensive predictions of community responses to multiple drivers, as only the adults are studied. A better understanding of the above biological processes is key for a grounded understanding of marine systems experiencing multiple driver impacts. With our improving knowledge, the focus of research is beginning to shift 
toward the community scale and toward a greater consideration of multiple biological aspects. This is a good basis for future research in the area.

\section{OUTLOOK FOR FUTURE RESEARCH: AN INTEGRATED APPROACH INCLUDING MULTIPLE DRIVER EFFECTS}

Mieszkowska et al. (2019) recently proposed a framework combining different approaches with the aim to improve the understanding of climate change impacts and subsequent species responses in coastal systems. This framework includes standardized data collection and integration of remote sensing, microclimate data, field experiments, citizen science, field surveys, and lab experiments in virtual data repositories, which then serve as a base for modeling, mapping, and managing approaches (Mieszkowska et al., 2019). However, they do not take multiple driver effects, as well as multidimensional stability into account. Throughout the review we have identified some research gaps, which may complement current frameworks if filled. Those research gaps relate to the inclusion of realistic climate change scenarios, the environmental and biological context, inclusion of multiple drivers and dimensions of stability, and adequate management approaches. Therefore, we propose to include the following aspects in further research, aiming to construct a more universal integrated approach (Figure 3).

\section{Environmental Context-Identification of Key Players and Drivers}

Although Crain et al. (2008) studied the different interaction types among ecosystems, it is still not possible to give defined predictions on the basis of introduced drivers or geographical position. How drivers affect an ecosystem is not only dependent on their structural complexity, but also on the environmental context in terms of other abiotic physical drivers in the systems, that can vary both spatially and temporally (Kroeker et al., 2017). Therefore, a good starting point for identifying key drivers is to first identify keystone species or species of particular interest (be it based on their commercial value, vulnerability to environmental changes, or other criteria). After identifying such organisms, we propose to subsequently explore their vulnerability and investigate historical changes in their population dynamics based on prior studies and existing data bases. Combined, this will help to identify key drivers and ultimately inform experimental treatments to investigate. Furthermore, transplant experiments and the use of Global Circulation Models (the latter particularly for temperature scenarios) can be an effective tool to further identify the margins for abiotic changes (Thompson et al., 2013; Hawkins et al., 2020; Korell et al., 2020).

\section{Realistic Climate Change Scenarios-Inclusion of Driver Fluctuations}

Climate-driven increases in frequency and amplitude of extreme events will shape marine populations non-predictively (Gonzalez and Holt, 2002). Recent papers have emphasized the need for climate change experiments, which correspond to realistic temperature increase ranges that will be prevalent over the coming decades and that are informed by climate projections (Hausfather and Peters, 2020; Korell et al., 2020). For a better understanding of how rocky shores will be affected, the inclusion of both fluctuations and mean values of temperature, $\mathrm{CO}_{2}$ level, and $\mathrm{pH}$ in experiments is, therefore, essential (Wernberg et al., 2013). As these parameters won't change uniformly over the globe we propose to use a combination of globalized and localized climate models in order to set realistic experimental variables for the location you want to apply your investigations to Allendorf et al. (2001) and Carrier-Belleau et al. (2021).

\section{Experimental Design-Prioritizing Research Efforts}

As mentioned throughout the review, multiple driver experiments are needed in order to disentangle individual effects (Crain et al., 2008) and for taking trophic levels into account (Seibold et al., 2018). As the multiplication of endless drivers is not feasible both in terms of complexity and resources (Boyd et al., 2018), we propose to prioritize research efforts. Relevant drivers, as well as sequences of occurrence and the identification of key players of a community may be considered in order to design feasible experiments. One possible solution to overcome both time and resource restrictions may be improved data sharing, i.e., an open data policy, as recently emphasized by Mieszkowska (2016) and Miyakawa (2020). Thereby, reproducibility of complex experiments will be secured and the reuse of data in a larger or different context promoted. At the same time, data from different case studies can be combined in order to detect global patterns, such as biodiversity change (e.g., BIOTIME, Dornelas et al., 2018).

\section{Dimensions of Stability-Measure Functional and Compositional Responses}

Considering the multiple dimensions of stability (Donohue et al., 2013) and measuring compositional and functional responses in experiments will elucidate the shifts in rocky shore assemblages under climate change (Cimon and Cusson, 2018). Because the growing body of literature shows that species richness in a system is relatively robust to changes, there is a need to measure functional diversity in a system as well (McGill et al., 2006; Hillebrand and Matthiessen, 2009; Cadotte et al., 2011). This is particularly important as a loss in functional diversity will likely be accompanied by a loss in ecosystem function (Mori et al., 2013).

\section{Management Solutions-Adequate Predictions for Informed Decision-Making}

In order to address current and emergent problems, there is a need for a better implementation of management approaches from the vast body of scientific literature. This is not only relevant for rocky shore intertidal systems, but also for other 


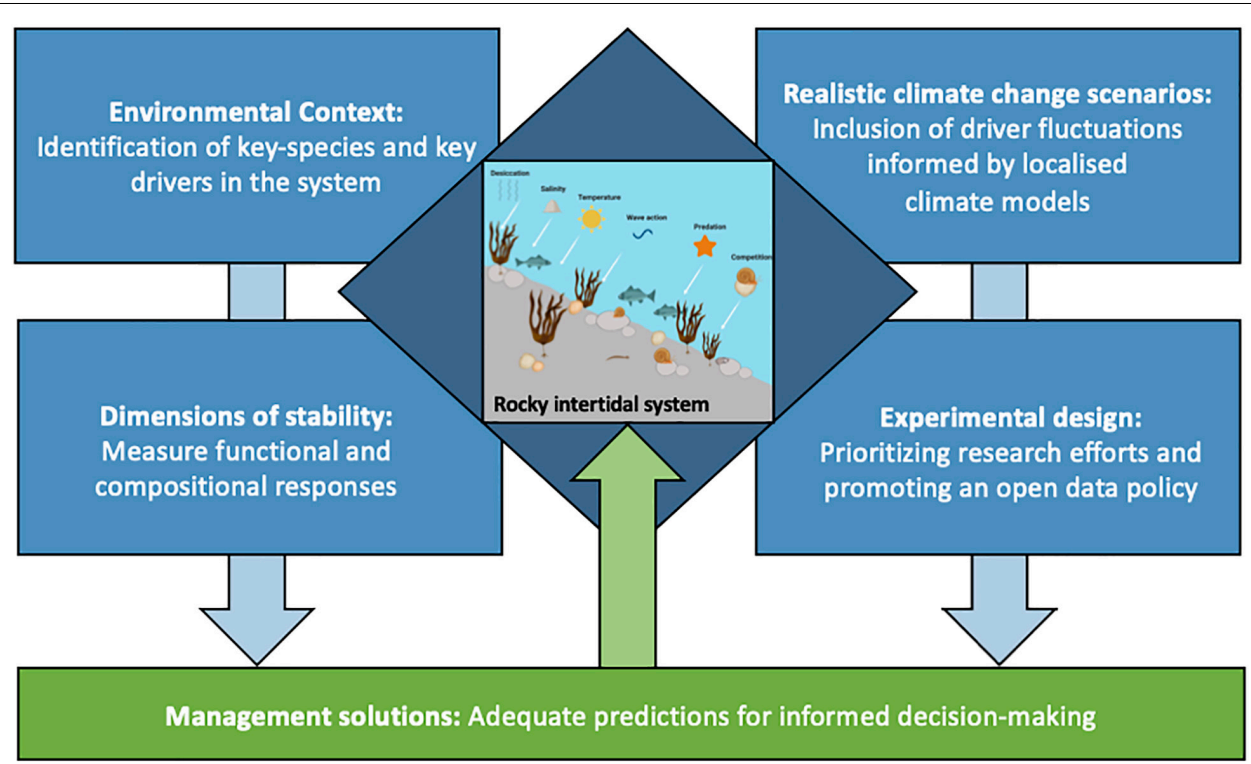

FIGURE 3 | An integrated approach for rocky intertidal systems, which should consider environmental context, realistic climate change scenarios, dimensions of stability and experimental design. Findings from the four areas combined can support improving management solutions toward conservation and sustainable use of rocky intertidal systems.

ecosystems and particularly in times of global change. Recent literature has highlighted research and management priorities for improving the current approaches to coastal and marine management, which should be considered in order to improve biodiversity conservation (e.g., Dreujou et al., 2020). In many cases, management actions will be more quickly and effectively implemented on a local level. Carrier-Belleau et al. (2021) propose management strategies on a local level in order to reduce those drivers that pose the largest potential stress for the system first, which can help to mitigate undesired effects of global change and provide a higher level of resilience. Proposed research priorities relate to the complexity of ecosystems and the importance of whole-system approaches. Holistic management approaches, therefore may support addressing multiple drivers of change and enabling the prioritization of management efforts. Ultimately, such holistic management interventions should also integrate social and economic dimensions (in addition to ecological components) to create a truly successful conservation approach (Dreujou et al., 2020).

\section{SUMMARY AND CONCLUSION}

Rocky shores are excellent model systems for understanding changes in community structure and function, and for investigating impacts of single and multiple drivers acting on them. Rocky intertidal systems are seemingly resilient to natural drivers and well adapted to frequent disturbances (Mieszkowska, 2016). A high biological diversity and a strong disturbance history often facilitate the recovery in rocky shores following a disturbance (Bernhardt and Leslie, 2013). However, even though species have evolved alongside natural drivers, extreme conditions can lead to shifts in community structure, as well as to a decreased ability to withstand changes in environmental conditions.

In this review, we have identified a number of natural and anthropogenic drivers and their interactions which may affect the natural resilience of rocky intertidal systems. We highlighted the need for a more holistic view on multiple driver impacts on rocky shores for understanding changes in community structure and ecological functioning.

We examined the current challenges facing multiple driver research in rocky shores, as multiple driver effects are still "ecological surprises," and showed that a growing body of literature is moving toward more complex experiments with two or more drivers. However, adding a large number of drivers is not trivial. Due to the complexity of multidriver experimental studies, there is a need to prioritize the relevant drivers in a system, as well as to realistically consider the frequency, magnitude, and sequence of selected drivers (Crain et al., 2008; Jackson et al., 2016; Boyd et al., 2018). Additionally, the biological aspects of ecosystems such as the community structure, presiding life forms, and the implementation of metabolic constrains of species should be integrated into multiple driver research to a greater extent because of their potential to alter the outcome of scenarios on rocky shore ecosystems.

Based on the literature, we therefore propose an integrated approach informing research on intertidal rocky shores that is complementary to the framework by Mieszkowska et al. (2019) and considers multiple driver effects as well as multidimensional stability in the environmental and biological context. Through data sharing, complementary research efforts can be aggregated, which will improve the ability to accurately predict rocky shore 
species responses to multiple driver scenarios driven by climate change, which will aid the development of suitable management and sustainability solutions.

\section{AUTHOR CONTRIBUTIONS}

LR led the writing. CK designed Figures 1-3. All authors contributed to the writing of the manuscript, idea, and design of the project.

\section{REFERENCES}

Allendorf, F. W., Leary, R. F., Spruell, P., and Wenburg, J. K. (2001). The problems with hybrids: Setting conservation guidelines. Trends Ecol. Evol. 16, 613-622. doi: 10.1016/S0169-5347(01)02290-X

Altamirano, M., Flores-Moya, A., and Figueroa, F. L. (2003). Effects of UV radiation and temperature on growth of germlings of three species of Fucus (Phaeophyceae). Aquat. Bot. 75, 9-20. doi: 10.1016/S0304-3770(02)00149-3

Arnott, S. E., and Vanni, M. J. (1993). Zooplankton assemblages in fishless bog lakes: Influence of biotic and abiotic factors. Ecology 74, 2361-2380. doi: 10. 2307/1939588

Ban, S. S., Graham, N. A. J., and Connolly, S. R. (2014). Evidence for multiple stressor interactions and effects on coral reefs. Glob. Chang. Biol. 20, 681-697. doi: $10.1111 /$ gcb.12453

Berkes, F., Colding, J., and Folke, C. (2004). Navigating social-ecological systems: building resilience for complexity and change. Biol. Conserv. 119:581. doi: 10 . 1016/j.biocon.2004.01.010

Bernhardt, J. R., and Leslie, H. M. (2013). Resilience to Climate Change in Coastal Marine Ecosystems. Ann. Rev. Mar. Sci. 5, 371-392. doi: 10.1146/annurevmarine-121211-172411

Bertocci, I., Arenas, F., Matias, M., Vaselli, S., Araújo, R., Abreu, H., et al. (2010). Canopy-forming species mediate the effects of disturbance onmacroalgal assemblages on Portuguese rocky shores. Mar. Ecol. Prog. Ser. 414, 107-116. doi: $10.3354 /$ meps08729

Blake, R. E., and Duffy, J. E. (2010). Grazer diversity affects resistance to multiple stressors in an experimental seagrass ecosystem. Oikos 119, 1625-1635. doi: 10.1111/j.1600-0706.2010.18419.x

Boyd, P. W., Collins, S., Dupont, S., Fabricius, K., Gattuso, J. P., Havenhand, J., et al. (2018). Experimental strategies to assess the biological ramifications of multiple drivers of global ocean change-A review. Glob. Chang. Biol. 24, 2239-2261. doi: $10.1111 /$ gcb.14102

Boyd, P. W., and Hutchins, D. A. (2012). Understanding the responses of ocean biota to a complex matrix of cumulative anthropogenic change. Mar. Ecol. Prog. Ser. 470, 125-135. doi: 10.3354/meps10121

Branch, G. M. (2001). "Rocky Shores," in Encyclopedia of Ocean Sciences. Netherland: Elsevier, 762-769. doi: 10.1016/B978-012374473-9.00086-2

Branch, G. M., Thompson, R. C., Crowe, T. P., Castilla, J. C., Langmead, O., and Hawkins, S. J. (2008). "Rocky intertidal shores: Prognosis for the future," in Aquatic Ecosystems: Trends and Global Prospects. Cambridge: Cambridge University Press, 209-225. doi: 10.1017/CBO9780511751790.020

Breitburg, D. L., Baxter, J. W., Hatfield, C. A., Howarth, R. W., Jones, C. G., Lovett, G. M., et al. (1998). "Understanding Effects of Multiple Stressors: Ideas and Challenges," in Successes, Limitations, and Frontiers in Ecosystem Science. New York, NY: Springer, 416-431. doi: 10.1007/978-1-4612-1724-4_17

Brooks, P. R., and Crowe, T. P. (2018). Density and biotic interactions modify the combined effects of global and local stressors. Oikos 127, 1746-1758. doi: 10.1111/oik.04459

Byrne, M. (2011). Impact of ocean warming and ocean acidification on marine invertebrate life history stages: Vulnerabilities and potential for persistence in a changing ocean. Oceanogr. Mar. Biol. An Annu. Rev. 49, 1-42.

Cadotte, M. W., Carscadden, K., and Mirotchnick, N. (2011). Beyond species: Functional diversity and the maintenance of ecological processes and services. J. Appl. Ecol. 48, 1079-1087. doi: 10.1111/j.1365-2664.2011.02048.x

\section{ACKNOWLEDGMENTS}

We would like to thank Samuel RP-J Ross and the two reviewers for their valuable input, as well as Simon Jungblut for his ceaseless support during the manuscript development and fine-tuning stages. Figures 1, 3 were created with BioRender.com. We thank Emily Guevara for final adjustments to the text. We would also like to express our endless gratitude to the organizers of the ICYMARE, especially Simon Jungblut and Viola Liebich, for their effort, time and heart-work and to the whole "ICYMARE family."

Carrier-Belleau, C., Drolet, D., McKindsey, C. W., and Archambault, P. (2021). Environmental stressors, complex interactions and marine benthic communities' responses. Sci. Rep. 11:4194. doi: 10.1038/s41598-021-83533-1

Cimon, S., and Cusson, M. (2018). Impact of multiple disturbances and stress on the temporal trajectories and resilience of benthic intertidal communities. Ecosphere 9:e02467. doi: 10.1002/ecs2.2467

Cole, V. J., Parker, L. M., O'Connor, S. J., O’Connor, W. A., Scanes, E., Byrne, M., et al. (2016). Effects of multiple climate change stressors: ocean acidification interacts with warming, hyposalinity, and low food supply on the larvae of the brooding flat oyster Ostrea angasi. Mar. Biol. 163:125. doi: 10.1007/s00227-0162880-4

Connell, J. H. (1961). The Influence of Interspecific Competition and Other Factors on the Distribution of the Barnacle Chthamalus Stellatus. Ecology 42, 710-723.

Connell, J. H. (1985). The consequences of variation in initial settlement vs. postsettlement mortality in rocky intertidal communities. J. Exp. Mar. Bio. Ecol. 93, 11-45. doi: 10.1016/0022-0981(85)90146-7

Connell, S. D., Doubleday, Z. A., Hamlyn, S. B., Foster, N. R., Harley, C. D. G., Helmuth, B., et al. (2017). How ocean acidification can benefit calcifiers. Curr. Biol. 27, R95-R96. doi: 10.1016/j.cub.2016.12.004

Cornwall, C. E., Revill, A. T., Hall-Spencer, J. M., Milazzo, M., Raven, J. A., and Hurd, C. L. (2017). Inorganic carbon physiology underpins macroalgal responses to elevated CO2. Sci. Rep. 7:46297. doi: 10.1038/srep46297

Côté, I. M., Darling, E. S., and Brown, C. J. (2016). Interactions among ecosystem stressors and their importance in conservation. Proc. R. Soc. B Biol. Sci. 283, 20152592. doi: 10.1098/rspb.2015.2592

Crain, C. M., Kroeker, K., and Halpern, B. S. (2008). Interactive and cumulative effects of multiple human stressors in marine systems. Ecol. Lett. 11, 1304-1315. doi: 10.1111/j.1461-0248.2008.01253.x

Crooks, K. R., and Soulé, M. E. (1999). Mesopredator release and avifaunal extinctions in a fragmented system. Nature 400, 563-566. doi: 10.1038/23028

Deutsch, C. A., Tewksbury, J. J., Huey, R. B., Sheldon, K. S., Ghalambor, C. K., Haak, D. C., et al. (2008). Impacts of climate warming on terrestrial ectotherms across latitude. Proc. Natl. Acad. Sci. U. S. A. 105, 6668-6672. doi: 10.1073/pnas. 0709472105

Doney, S. C., Ruckelshaus, M., Emmett Duffy, J., Barry, J. P., Chan, F., English, C. A., et al. (2012). Climate change impacts on marine ecosystems. Ann. Rev. Mar. Sci. 4, 11-37. doi: 10.1146/annurev-marine-041911-111611

Donohue, I., Petchey, O. L., Montoya, J. M., Jackson, A. L., Mcnally, L., Viana, M., et al. (2013). On the dimensionality of ecological stability. Ecol. Lett. 16, 421-429. doi: 10.1111/ele.12086

Dornelas, M., Antão, L. H., Moyes, F., Bates, A. E., Magurran, A. E., Adam, D., et al. (2018). BioTIME: A database of biodiversity time series for the Anthropocene. Glob. Ecol. Biogeogr. 27, 760-786. doi: 10.1111/geb.12729

Dreujou, E., Carrier-Belleau, C., Goldsmit, J., Fiorentino, D., Ben-Hamadou, R., Muelbert, J. H., et al. (2020). Holistic Environmental Approaches and Aichi Biodiversity Targets: accomplishments and perspectives for marine ecosystems. PeerJ. 8:e8171. doi: 10.7717/peerj.8171

Espinel-Velasco, N., Hoffmann, L., Agüera, A., Byrne, M., Dupont, S., Uthicke, S., et al. (2018). Effects of ocean acidification on the settlement and metamorphosis of marine invertebrate and fish larvae: A review. Mar. Ecol. Prog. Ser. 606, 237-257. doi: 10.3354/meps12754

Findlay, H. S., Wood, H. L., Kendall, M. A., Spicer, J. I., Twitchett, R. J., and Widdicombe, S. (2009). Calcification, a physiological process to be considered 
in the context of the whole organism. Biogeosci. Discuss. 6, 2267-2284. doi: 10.5194/bgd-6-2267-2009

Folt, C. L., Chen, C. Y., Moore, M. V., and Burnaford, J. (1999). Synergism and antagonism among multiple stressors. Limnol. Oceanogr. 44, 864-877. doi: 10. 4319/lo.1999.44.3_part_2.0864

Fong, C. R., and Fong, P. (2018). Nutrient Fluctuations in Marine Systems: Press Versus Pulse Nutrient Subsidies Affect Producer Competition and Diversity in Estuaries and Coral Reefs. Estuaries Coasts 41, 421-429. doi: 10.1007/s12237017-0291-5

Gonzalez, A., and Holt, R. D. (2002). The inflationary effects of environmental fluctuations in source-sink systems. Proc. Natl. Acad. Sci. U. S. A. 99, 1487214877. doi: $10.1073 /$ pnas.232589299

Griffin, J. N., O’Gorman, E. J., Emmerson, M. C., Jenkins, S. R., Klein, A. M., Loreau, M., et al. (2009). Biodiversity, Ecosystem Functioning, and Human Wellbeing: An Ecological and Economic Perspective, Oxford: Oxford Scholarship Online. doi: 10.1093/acprof:oso/9780199547951.003.0006

Guenther, R., Miklasz, K., Carrington, E., and Martone, P. T. (2018). Macroalgal spore dysfunction: ocean acidification delays and weakens adhesion. J. Phycol. 54, 153-158. doi: 10.1111/jpy.12614

Gunderson, A. R., Armstrong, E. J., and Stillman, J. H. (2016). Multiple Stressors in a Changing World: The Need for an Improved Perspective on Physiological Responses to the Dynamic Marine Environment. Ann. Rev. Mar. Sci. 8, 357378. doi: 10.1146/annurev-marine-122414-033953

Halpern, B. S., Frazier, M., Potapenko, J., Casey, K. S., Koenig, K., Longo, C., et al. (2015). Spatial and temporal changes in cumulative human impacts on the world's ocean. Nat. Commun. 6, 1-7. doi: 10.1038/ncomms8615

Harley, C. D. G., Hughes, A. R., Hultgren, K. M., Miner, B. G., Sorte, C. J. B., Thornber, C. S., et al. (2006). The impacts of climate change in coastal marine systems. Ecol. Lett. 9, 228-241. doi: 10.1111/j.1461-0248.2005.00871.x

Hausfather, Z., and Peters, G. P. (2020). Emissions - the 'business as usual' story is misleading. Nature 577, 618-620. doi: 10.1038/d41586-020-00177-3

Hawkins, S. J., Evans, A. J., Mieszkowska, N., Adams, L. C., Bray, S., Burrows, M. T., et al. (2017). Distinguishing globally-driven changes from regional- and local-scale impacts: The case for long-term and broad-scale studies of recovery from pollution. Mar. Pollut. Bull. 124, 573-586. doi: 10.1016/j.marpolbul.2017. 01.068

Hawkins, S. J., Moore, P. J., Burrows, M. T., Poloczanska, E., Mieszkowska, N., Herbert, R. J. H., et al. (2008). Complex interactions in a rapidly changing world: Responses of rocky shore communities to recent climate change. Clim. Res. 37, 123-133. doi: 10.3354/cr00768

Hawkins, S. J., Pack, K. E., Hyder, K., Benedetti-Cecchi, L., and Jenkins, S. R. (2020). Rocky shores as tractable test systems for experimental ecology. J. Mar. Biol. Assoc. U. K. 100, 1017-1041. doi: 10.1017/S0025315420001046

Helmuth, B., Harley, C. D. G., Halpin, P. M., O’Donnell, M., Hofmann, G. E., and Blanchette, C. A. (2002). Climate change and latitudinal patterns of intertidal thermal stress. Science 298, 1015-1017. doi: 10.1126/science.1076814

Helmuth, B., Mieszkowska, N., Moore, P., and Hawkins, S. J. (2006). Living on the edge of two changing worlds: Forecasting the responses of rocky intertidal ecosystems to climate change. Annu. Rev. Ecol. Evol. Syst. 37, 373-404. doi: 10.1146/annurev.ecolsys.37.091305.110149

Hillebrand, H., and Kunze, C. (2020). Meta-analysis on pulse disturbances reveals differences in functional and compositional recovery across ecosystems. Ecol. Lett. 23, 575-585. doi: 10.1111/ele.13457

Hillebrand, H., Langenheder, S., Lebret, K., Lindström, E., Östman, Ö, and Striebel, M. (2018). Decomposing multiple dimensions of stability in global change experiments. Ecol. Lett 21, 21-30. doi: 10.1111/ele.12867

Hillebrand, H., and Matthiessen, B. (2009). Biodiversity in a complex world: Consolidation and progress in functional biodiversity research. Ecol. Lett. 12, 1405-1419. doi: 10.1111/j.1461-0248.2009.01388.x

Hoegh-Guldberg, O., Jacob, D., Taylor, M., Bindi, S., Brown, I., Camilloni, A., et al. (2018). Impacts of $1.5^{\circ} \mathrm{C}$ of Global Warming on Natural and Human Systems. URL: https://www.ipcc.ch/sr15

Holbrook, N. J., Scannell, H. A., Sen Gupta, A., Benthuysen, J. A., Feng, M., Oliver, E. C. J., et al. (2019). A global assessment of marine heatwaves and their drivers. Nat. Commun. 10:2624. doi: 10.1038/s41467-019-10206-z

Hughes, T. P., and Connell, J. H. (1999). Multiple stressors on coral reefs: A longterm perspective. Limnol. Oceanogr. 44, 932-940. doi: 10.4319/lo.1999.44.3_ part_2.0932
Hughes, T. P., Kerry, J. T., Baird, A. H., Connolly, S. R., Chase, T. J., Dietzel, A., et al. (2019). Global warming impairs stock-recruitment dynamics of corals. Nature 568, 387-390. doi: 10.1038/s41586-019-1081-y

Jackson, J. B. C., Kirby, M. X., Berger, W. H., Bjorndal, K. A., Botsford, L. W., Bourque, B. J., et al. (2001). Historical overfishing and the recent collapse of coastal ecosystems. Science 293, 629-637. doi: 10.1126/science.1059199

Jackson, M. C., Loewen, C. J. G., Vinebrooke, R. D., and Chimimba, C. T. (2016). Net effects of multiple stressors in freshwater ecosystems: A meta-analysis. Glob. Chang. Biol. 22, 180-189. doi: 10.1111/gcb.13028

Jackson, M. C., Pawar, S., and Woodward, G. (2021). The Temporal Dynamics of Multiple Stressor Effects: From Individuals to Ecosystems. Trends Ecol. Evol 36, 402-410. doi: 10.1016/j.tree.2021.01.005

Johnson, V. R., Brownlee, C., Milazzo, M., and Hall-Spencer, J. M. (2015). Marine microphytobenthic assemblage shift along a natural shallow-water $\mathrm{CO} 2$ gradient subjected to multiple environmental stressors. J. Mar. Sci. Eng. 3, 1425-1447. doi: 10.3390/jmse3041425

Kéfi, S., Domínguez-García, V., Donohue, I., Fontaine, C., Thébault, E., and Dakos, V. (2019). Advancing our understanding of ecological stability. Ecol. Lett. 22, 1349-1356. doi: 10.1111/ele.13340

Ko, G. W. K., Dineshram, R., Campanati, C., Chan, V. B. S., Havenhand, J., and Thiyagarajan, V. (2014). Interactive effects of ocean acidification, elevated temperature, and reduced salinity on early-life stages of the pacific oyster. Environ. Sci. Technol. 48, 10079-10088. doi: 10.1021/es501611u

Korell, L., Auge, H., Chase, J. M., Harpole, S., and Knight, T. M. (2020). We need more realistic climate change experiments for understanding ecosystems of the future. Glob. Chang. Biol. 26, 325-327. doi: 10.1111/gcb.14797

Kroeker, K. J., Bell, L. E., Donham, E. M., Hoshijima, U., Lummis, S., Toy, J. A., et al. (2020). Ecological change in dynamic environments: Accounting for temporal environmental variability in studies of ocean change biology. Glob. Chang. Biol. 26, 54-56. doi: $10.1111 / \mathrm{gcb} .14868$

Kroeker, K. J., Kordas, R. L., and Harley, C. D. G. (2017). Embracing interactions in ocean acidification research: Confronting multiple stressor scenarios and context dependence. Biol. Lett. 13:20160802. doi: 10.1098/rsbl.2016.0802

Loreau, M. (2004). Does functional redundancy exist? Oikos 104, 606-611. doi: 10.1111/j.0030-1299.2004.12685.x

Manríquez, P. H., Jara, M. E., Seguel, M. E., Torres, R., Alarcon, E., and Lee, M. R. (2016). Ocean acidification and increased temperature have both positive and negative effects on early ontogenetic traits of a rocky shore keystone predator species. PLoS One 11:e0151920. doi: 10.1371/journal.pone.01 51920

McGill, B. J., Enquist, B. J., Weiher, E., and Westoby, M. (2006). Rebuilding community ecology from functional traits. Trends Ecol. Evol. 21, 178-185. doi: $10.1016 /$ j.tree.2006.02.002

Menge, B. A. (1976). Organization of the New England Rocky Intertidal Community: Role of Predation. Competition, and Environmental Heterogeneity. Ecol. Monogr. 46, 355-393. doi: 10.2307/1942563

Micheli, F., Heiman, K. W., Kappel, C. V., Martone, R. G., Sethi, S. A., Osio, G. C., et al. (2016). Combined impacts of natural and human disturbances on rocky shore communities. Ocean Coast. Manag. 126, 42-50. doi: 10.1016/ j.ocecoaman.2016.03.014

Mieszkowska, N. (2016). Climate Change: Observed Impacts on Planet Earth, Second Edition Edn, Netherland: Elsevier, 213-229. doi: 10.1016/B978-0-44463524-2.00014-2

Mieszkowska, N., Benedetti-Cecchi, L., Burrows, M. T., Mangano, M. C., Queirós, A., Seuront, L., et al. (2019). Multinational, integrated approaches to forecasting and managing the impacts of climate change on intertidal species. Mar. Ecol. Prog. Ser. 613, 247-252. doi: 10.3354/meps12902

Millero, F., Woosley, R., DiTrolio, B., and Waters, J. (2009). Effect of Ocean Acidification on the Speciation of Metals in Seawater. Oceanography 22, 72-85. doi: 10.5670/oceanog. 2009.98

Miyakawa, T. (2020). No raw data, no science: another possible source of the reproducibility crisis. Mol. Brain 13:24. doi: 10.1186/s13041-020-0552-2

Mori, A. S., Furukawa, T., and Sasaki, T. (2013). Response diversity determines the resilience of ecosystems to environmental change. Biol. Rev. 88, 349-364. doi: 10.1111/brv.12004

Mrowicki, R. J., O'Connor, N. E., and Donohue, I. (2016). Temporal variability of a single population can determine the vulnerability of communities to perturbations. J. Ecol. 104, 887-897. doi: 10.1111/1365-2745.12533 
Naeem, S. (2008). Species Redundancy and Ecosystem Reliability. Conserv. Biol. 12, 39-45. doi: 10.1111/j.1523-1739.1998.96379.x

Nardone, J. A., Patel, S., Siegel, K. R., Tedesco, D., McNicholl, C. G., O’Malley, J., et al. (2018). Assessing the impacts of ocean acidification on adhesion and shell formation in the Barnacle Amphibalanus amphitrite. Front. Mar. Sci. 5:369. doi: 10.3389/fmars.2018.00369

Nõges, P., Argillier, C., Borja, Á, Garmendia, J. M., Hanganu, J., Kodeš, V., et al. (2016). Quantified biotic and abiotic responses to multiple stress in freshwater, marine and ground waters. Sci. Total Environ. 540, 43-52. doi: 10.1016/j. scitotenv.2015.06.045

Nyström, M., and Folke, C. (2001). Spatial resilience of coral reefs. Ecosystems 4, 406-417. doi: 10.1007/s10021-001-0019-y

O'Connor, N. E., Bracken, M. E. S., Crowe, T. P., and Donohue, I. (2015). Nutrient enrichment alters the consequences of species loss. J. Ecol. 103, 862-870. doi: $10.1111 / 1365-2745.12415$

O'Connor, N. E., and Donohue, I. (2013). Environmental context determines multi-trophic effects of consumer species loss. Glob. Chang. Biol. 19, 431-440. doi: $10.1111 / \mathrm{gcb} .12061$

Oliver, E. C. J. (2019). Mean warming not variability drives marine heatwave trends. Clim. Dyn. 53, 1653-1659. doi: 10.1007/s00382-019-04707-2

Oliver, E. C. J., Donat, M. G., Burrows, M. T., Moore, P. J., Smale, D. A., Alexander, L. V., et al. (2018). Longer and more frequent marine heatwaves over the past century. Nat. Commun. 9:1324. doi: 10.1038/s41467-018-03732-9

Orr, J. A., Vinebrooke, R. D., Jackson, M. C., Kroeker, K. J., Kordas, R. L., Mantyka-Pringle, C., et al. (2020). Towards a unified study of multiple stressors: Divisions and common goals across research disciplines. Proc. R. Soc. B Biol. Sci. 287:20200421. doi: 10.1098/rspb.2020.0421

Paine, R. T. (1974). Intertidal community structure - Experimental studies on the relationship between a dominant competitor and its principal predator. Oecologia 15, 93-120. doi: 10.1007/BF00345739

Piggott, J. J., Townsend, C. R., and Matthaei, C. D. (2015). Reconceptualizing synergism and antagonism among multiple stressors. Ecol. Evol. 5, 1538-1547. doi: 10.1002/ece3.1465

Pimm, S. L. (1984). The complexity and stability of ecosystems. Nature 307, 321-326. doi: 10.1038/307321a0

Pitt, N. R., Poloczanska, E. S., and Hobday, A. J. (2010). Climate-driven range changes in Tasmanian intertidal fauna. Mar. Freshw. Res. 61, 963-970. doi: 10.1071/MF09225

Przeslawski, R., Byrne, M., and Mellin, C. (2015). A review and meta-analysis of the effects of multiple abiotic stressors on marine embryos and larvae. Glob. Chang. Biol. 21, 2122-2140. doi: 10.1111/gcb.12833

Przeslawski, R., Davis, A. R., and Benkendorff, K. (2005). Synergistic effects associated with climate change and the development of rocky shore molluscs. Glob. Chang. Biol. 11, 515-522. doi: 10.1111/j.1365-2486.2005.00918.x

Queirós, A. M., Fernandes, J. A., Faulwetter, S., Nunes, J., Rastrick, S. P. S., Mieszkowska, N., et al. (2015). Scaling up experimental ocean acidification and warming research: From individuals to the ecosystem. Glob. Chang. Biol. 21, 130-143. doi: $10.1111 / \mathrm{gcb} .12675$

Ross, P. M., Parker, L., O'Connor, W. A., and Bailey, E. A. (2011). The impact of ocean acidification on reproduction, early development and settlement of marine organisms. Water 3, 1005-1030. doi: 10.3390/w3041005

Sampaio, E., Lopes, A. R., Francisco, S., Paula, J. R., Pimentel, M., Maulvault, A. L., et al. (2018). Ocean acidification dampens physiological stress response to warming and contamination in a commercially-important fish (Argyrosomus regius). Sci. Total Environ. 618, 388-398. doi: 10.1016/j.scitotenv.2017.11.059

Seibold, S., Cadotte, M. W., MacIvor, J. S., Thorn, S., and Müller, J. (2018). The Necessity of Multitrophic Approaches in Community Ecology. Trends Ecol. Evol. 33, 754-764. doi: 10.1016/j.tree.2018.07.001

Smale, D. A., Wernberg, T., Oliver, E. C. J., Thomsen, M., Harvey, B. P., Straub, S. C., et al. (2019). Marine heatwaves threaten global biodiversity and the provision of ecosystem services. Nat. Clim. Chang. 9, 306-312. doi: 10.1038/ s41558-019-0412-1

Smale, D. A., Wernberg, T., and Vanderklift, M. A. (2017). Regional-scale variability in the response of benthic macroinvertebrate assemblages to a marine heatwave. Mar. Ecol. Prog. Ser. 568, 17-30. doi: 10.3354/meps12080

Stachowicz, J. J., Terwin, J. R., Whitlatch, R. B., and Osman, R. W. (2002). Linking climate change and biological invasions: Ocean warming facilitates nonindigenous species invasions. Proc. Natl. Acad. Sci. U. S. A. 99, 1549715500. doi: 10.1073/pnas. 242437499

Staehr, P. A., and Sand-Jensen, K. A. J. (2006). Seasonal changes in temperature and nutrient control of photosynthesis, respiration and growth of natural phytoplankton communities. Freshw. Biol 51, 249-262. doi: 10.1111/j.13652427.2005.01490.x

Stockbridge, J., Jones, A. R., and Gillanders, B. M. (2020). A meta-analysis of multiple stressors on seagrasses in the context of marine spatial cumulative impacts assessment. Sci. Rep. 10:11934. doi: 10.1038/s41598-020-68 801-w

Stocker, T. F., Qin, D., Plattner, G. K., Tignor, M. M. B., Allen, S. K., Boschung, J., et al. (2013). Climate change 2013 the physical science basis: Working Group I contribution to the fifth assessment report of the intergovernmental panel on climate change. Cambridge: Cambridge University Press, doi: 10.1017/ CBO9781107415324

Strain, E. M. A., Van Belzen, J., Van Dalen, J., Bouma, T. J., and Airoldi, L. (2015). Management of local stressors can improve the resilience of marine canopy algae to global stressors. PLoS One 10:e0120837. doi: 10.1371/journal.pone. 0120837

Thiyagarajan, V., Harder, T., and Qian, P. Y. (2003). Combined effects of temperature and salinity on larval development and attachment of the subtidal barnacle Balanus trigonus Darwin. J. Exp. Mar. Bio. Ecol. 287, 223-236. doi: 10.1016/S0022-0981(02)00570-1

Thompson, R. C., Crowe, T. P., and Hawkins, S. J. (2002). Rocky intertidal communities: Past environmental changes, present status and predictions for the next 25 years. Environ. Conserv. 29, 168-191. doi: 10.1017/ S0376892902000115

Thompson, R. M., Beardall, J., Beringer, J., Grace, M., and Sardina, P. (2013). Means and extremes: Building variability into community-level climate change experiments. Ecol. Lett. 16, 799-806. doi: 10.1111/ele.12095

Thomsen, M. S., Mondardini, L., Alestra, T., Gerrity, S., Tait, L., South, P. M., et al. (2019). Local Extinction of bull kelp (Durvillaea spp.) due to a marine heatwave. Front. Mar. Sci 6:84. doi: 10.3389/fmars.2019.00084

Tilman, D., Wedin, D., and Knops, J. (1996). Productivity and sustainability influenced by biodiversity in grassland ecosystems. Nature 379, 718-720. doi: $10.1038 / 379718 \mathrm{a} 0$

Townsend, C. R., Scarsbrook, M. R., and Dolédec, S. (1997). The intermediate disturbance hypothesis, refugia, and biodiversity in streams. Limnol. Oceanogr. 42, 938-949. doi: 10.4319/lo.1997.42.5.0938

Underwood, A. J. (1972). Tide-model analysis of the zonation of intertidal prosobranches. II. Four species of trochids (Gastropoda: Prosobranchia). J. Exp. Mar. Bio. Ecol. 9, 257-277. doi: 10.1016/0022-0981(72)90037-8

Underwood, A. J. (1981). Structure of a rocky intertidal community in New South Wales: Patterns of vertical distribution and seasonal changes. J. Exp. Mar. Bio. Ecol. 51, 57-85. doi: 10.1016/0022-0981(81)90154-4

Ushakova, O. O. (2003). Combined effect of salinity and temperature on Spirorbis spirorbis L. and Circeus spirillum L. larvae from the White Sea. J. Exp. Mar. Bio. Ecol. 296, 23-33. doi: 10.1016/S0022-0981(03)00301-0

Vinebrooke, R. D., Cottingham, K. L., Norberg, J., Scheffer, M., Dodson, S. I., Maberly, S. C., et al. (2004). Impacts of multiple stressors on biodiversity and ecosystem functioning: The role of species co-tolerance. Oikos 104, 451-457. doi: $10.1111 / j .0030-1299.2004 .13255 . x$

Vye, S. R., Emmerson, M. C., Arenas, F., Dick, J. T. A., and O'Connor, N. E. (2015). Stressor intensity determines antagonistic interactions between species invasion and multiple stressor effects on ecosystem functioning. New York: Wiley-Blackwell, doi: 10.1111/oik.01583

Vye, S. R., Emmerson, M. C., Dick, J. T. A., and O'Connor, N. E. (2017). Cumulative effects of multiple stressors: An invasive oyster and nutrient enrichment reduce subsequent invasive barnacle recruitment. J. Exp. Mar. Bio. Ecol. 486, 322-327. doi: 10.1016/j.jembe.2016.10.021

Walker, B. (1995). Conserving Biological Diversity through Ecosystem Resilience. Conserv. Biol. 9, 747-752. doi: 10.1046/j.1523-1739.1995.09040747.x

Walter, J., Jentsch, A., Beierkuhnlein, C., and Kreyling, J. (2013). Ecological stress memory and cross stress tolerance in plants in the face of climate extremes. Environ. Exp. Bot. 94, 3-8. doi: 10.1016/j.envexpbot.2012.02.009

Wernberg, T., Russell, B. D., Moore, P. J., Ling, S. D., Smale, D. A., Campbell, A., et al. (2011). Impacts of climate change in a global hotspot for temperate 
marine biodiversity and ocean warming. J. Exp. Mar. Bio. Ecol. 400, 7-16. doi: 10.1016/j.jembe.2011.02.021

Wernberg, T., Smale, D. A., Tuya, F., Thomsen, M. S., Langlois, T. J., De Bettignies, T., et al. (2013). An extreme climatic event alters marine ecosystem structure in a global biodiversity hotspot. Nat. Clim. Chang. 3, 78-82. doi: 10.1038/ nclimate 1627

White, L., Donohue, I., Emmerson, M. C., and O'Connor, N. E. (2018). Combined effects of warming and nutrients on marine communities are moderated by predators and vary across functional groups. Glob. Chang. Biol. 24, 5853-5866. doi: $10.1111 / \mathrm{gcb} .14456$

White, L., O’Connor, N. E., Yang, Q., Emmerson, M. C., and Donohue, I. (2020). Individual species provide multifaceted contributions to the stability of ecosystems. Nat. Ecol. Evol. 4, 1594-1601. doi: 10.1038/s41559-020-01315-w

Wong, B. B. M., and Candolin, U. (2015). Behavioral responses to changing environments. Behav. Ecol. 26, 665-673. doi: 10.1093/beheco/aru183

Worm, B., and Karez, R. (2002). "Competition, Coexistence and Diversity on Rocky Shores," in Ecological Studies. (Berlin, Heidelberg. Berlin: Springer, 133-163. doi: 10.1007/978-3-642-56166-5_6
Yachi, S., and Loreau, M. (1999). Biodiversity and ecosystem productivity in a fluctuating environment: The insurance hypothesis. Proc. Natl. Acad. Sci. U. S. A. 96, 1463-1468. doi: 10.1073/pnas.96.4.1463

Zweng, R. C., Koch, M. S., and Bowes, G. (2018). The role of irradiance and C-use strategies in tropical macroalgae photosynthetic response to ocean acidification. Sci. Rep 8:9479. doi: 10.1038/s41598-018-27333-0

Conflict of Interest: The authors declare that the research was conducted in the absence of any commercial or financial relationships that could be construed as a potential conflict of interest.

Copyright (c) 2021 Kunze, Wölfelschneider and Rölfer. This is an open-access article distributed under the terms of the Creative Commons Attribution License (CC BY).

The use, distribution or reproduction in other forums is permitted, provided the original author(s) and the copyright owner(s) are credited and that the original publication in this journal is cited, in accordance with accepted academic practice. No use, distribution or reproduction is permitted which does not comply with these terms. 